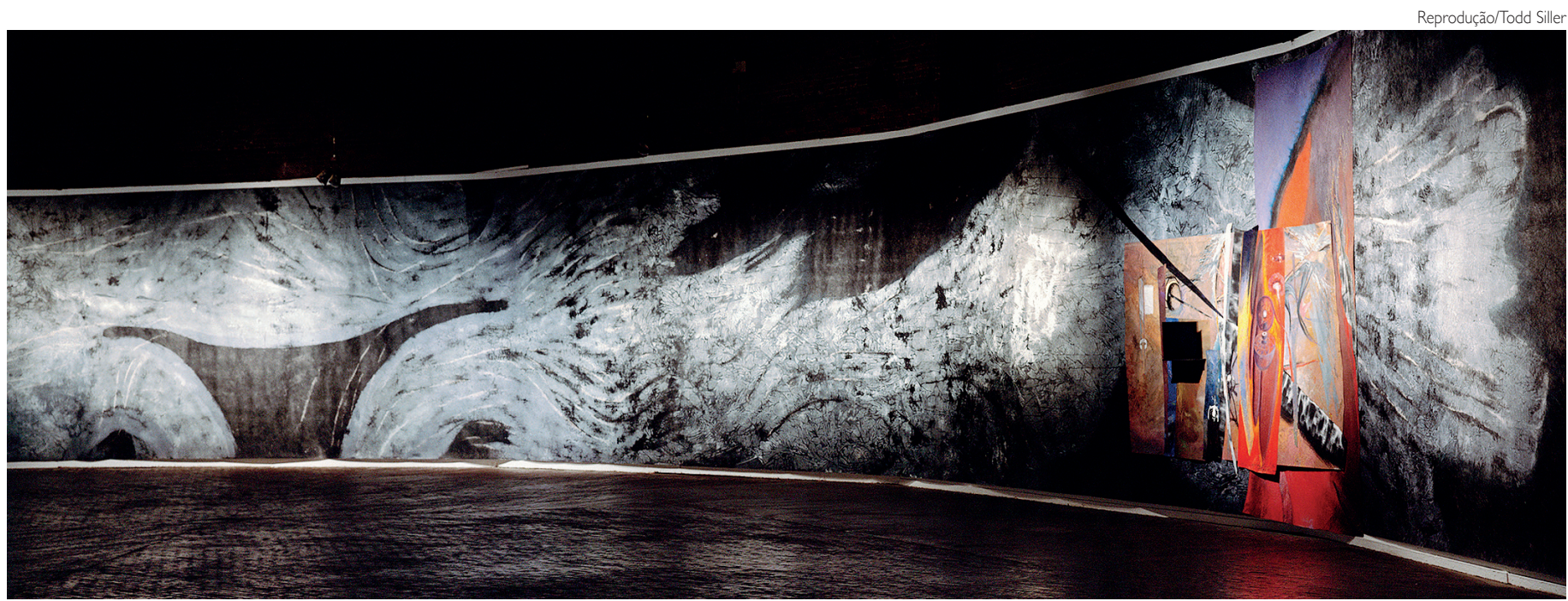

Obra The brain theater of mental imagery (1984-84), de Todd Siler, um dos autores do Artscience Manifesto

\title{
INTERDISCIPLINARIDADE
}

\section{ARTE E CIÊNCIA PARA LIDAR COM UM MUNDO COMPLEXO}

Em 1959, o físico e romancista inglês Charles Percy Snow expressou preocupação com o abismo que crescia continuamente entre as áreas de humanidades e as de ciências naturais, o que ele chamou de "duas culturas". Talvez o escritor ficasse menos aflito ao ver o número de pontes construídas sobre esse abismo décadas depois. Uma delas está sendo pavimentada pelas pesquisas e trabalhos da área de arteciência: "uma nova forma de explorar a cultura e a sociedade que integra a experiência sinestésica e exploração analítica. É conhecer, analisar, experimentando e sentindo, simultaneamente", de acordo com o texto do "ArtScience Manifesto", documento assinado em 2011 pelos pesquisadores Adam Brown,
Bob Root-Bernstein e pelos arte-cientistas Todd Siler e Kenneth Snelson.

Para esses pesquisadores, o futuro da humanidade e da sociedade civil depende de conexôes e a arteciência faz isso, ela conecta, ampliando a capacidade de criação humana. "O movimento Steam (ciência, tecnologia, engenharias, artes e matemática, na sigla em inglês) é uma forma de reintroduzir habilidades criativas e de comunicação no currículo científico", afirma Robert Root-Bernstein, professor de fisiologia na Michigan State University (MSU). Para ele, isso é essencial para construir um mundo não apenas mais interessante, mas mais perceptível em sua complexidade. A compartimentação das áreas do conhecimento “torna as coisas mais fáceis, mas isso não necessariamente é o que desejamos. Queremos um engenheiro que construa uma ponte que não caia, mas também que ele consiga pensar em usar materiais e técnicas que ninguém havia pensado antes", diz. Além de estudos sobre Aids e biologia molecular, Root-Bernstein é um aficionado pelo processo criativo na arte e suas possíveis intersecções com a ciência.

DIÁLOGoS Os pontos de encadeamento entre arte e ciência não costumam estar nos lugares óbvios. Segundo João Silveira, pesquisador visitante na Faculdade de Artes e Ciências da Universidade Harvard e arte-cientista residente no Le Laboratoire Cambridge, "as conexões entre arte e ciência não são muito fáceis de serem vistas quando se tem em mente o produto final, mas podem ser bastante compreendidas quando se pensa na metodologia de criação dessas áreas", explica. "Embora o método científico exija um 


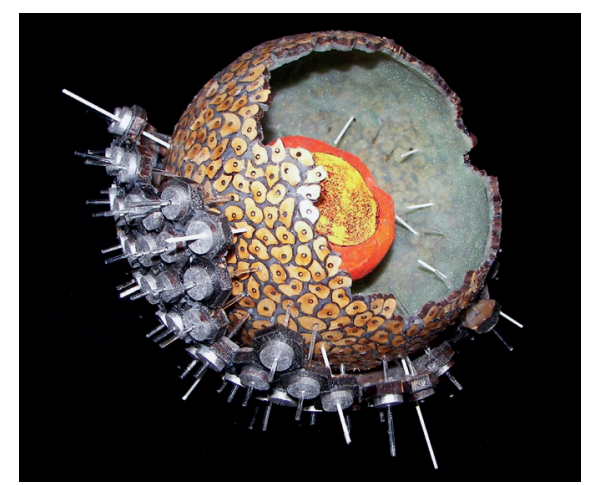

Acima, Fractal reactor re-creating the sun e à direita The symetries of nature. Em seu trabalho, Siller explora conexões entre física e artes plásticas

protocolo, há indicações dos mais renomados cientistas de que o fazer científico precisa da criatividade, inspiração e de potencial inventivo". O que não é muito diferente nas artes: "apesar da maior liberdade metodológica e de não precisar se comprometer com a reprodutibilidade, como acontece no método científico, existe uma metodologia para se fazer arte", afirma Silveira. Estas conexões entre método e técnica podem estar causando fissuras nos espaços que distanciam cientistas e artistas, abrindo portas para novos diálogos.

Para Adam Brown, que também é professor associado da MSU e um dos idealizadores do "ArtScience Manifesto", é importante que os colaboradores de uma área entendam a linguagem e as limitações das outras. Isso possibilita que a comunicação aconteça em um nível profundo. "Só assim seremos capazes de lidar com problemas complexos de um mundo em ebulição", afirma Brown, que criou uma área de estudo na qual leciona na MSU chamada arte, eletrônica e intermídia.

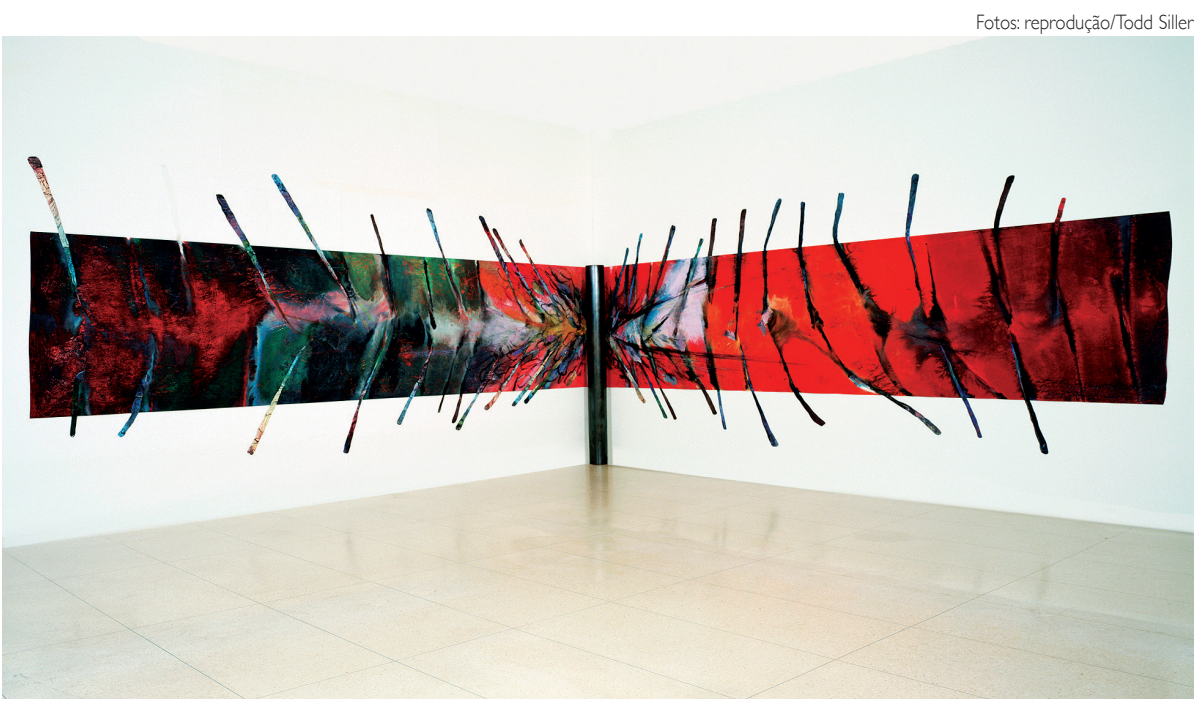

SIMPLES COMPLEXIDADE Mesclar áreas ou temáticas diferentes não envolve uma simples justaposição, onde cada disciplina traz seu ponto de vista sobre um único objeto. Há várias combinações possíveis. Talvez uma das definiçỗes mais elucidativas sobre o assunto foi a do físico romeno Basarab Nicolescu quando ele usou os termos: pluridisciplinaridade, interdisciplinaridade e a que ele mais defende, a transdisciplinaridade. A pluridisciplinaridade diz respeito a um objeto que é analisado por mais de uma disciplina - ou tem sobre ela diversos pontos de vista. A interdisciplinaridade implica na utilização de técnicas de um campo do saber por outro. Já a transdisciplinaridade ultrapassa as barreiras que separam uma disciplina da outra, tornando mais fluídos os diversos campos do saber - sem que eles deixem de existir.

Disciplinas explorando a inter, pluri e transdisciplinaridade são mais comuns em programas de pós-graduação. No entanto, já existem programas de graduação que buscam unir arte e ciência. Um exemplo é o curso de artes e ciências da University College London (UCL). "Me parece um pouco tarde estudar a partir desses pressupostos na pós-graduação se você quer realmente entender estas coisas", questiona o diretor do programa, Carl Gombrich. Mas será que, quando for necessário resolver problemas da vida real, seja nas artes, humanidades ou ciências naturais e sociais, não seria importante ter algum tipo de especialização? Para Gombrich, "a única maneira de ser um cientista efetivo/eficiente, hoje, é ser interdisciplinar - ou o profissional não vai saber como implementar sua ciência no mundo real". Misturar disciplinas desde a base, continua ele, "não tem a ver com a preocupação em ser um especialista em determinada disciplina à moda antiga, já que estão surgindo especialistas em novas disciplinas", aponta. $\mathrm{Ou}$, nas palavras de Silveira, "para resolver problemas complexos é necessário pensar de forma complexa, o que pode ser simples".

Meghie Rodrigues 